\title{
THE ROLE OF COLORED ACCESSORY BRACTS IN THE REPRODUCTIVE BIOLOGY OF LAVANDULA STOECHAS
}

\author{
JAVIER HERRERA \\ Departamento de Biología Vegetal y Ecología, Universidad de Sevilla, Apartado 1095, E-41080 Sevilla, Spain
}

\begin{abstract}
This study investigates the role played by showy structures in the reproduction of Lavandula stoechas L. (Lamiaceae), a self-compatible Mediterranean shrub with compact, head-like inflorescences that are terminated by a tuft of conspicuous pink bracts. Pollinator visitation rates to plants with bracts correlated positively with that of paired, treated shrubs with all their bracts removed and, overall, bractless and control plants had equivalent visitation rates. In experimentally split shrubs, however, a strong effect on pollinator choice was evident, and distant visitor approaches were most often to that side keeping the attractive organs. Fecundity was not depressed in plants with reduced visual displays, and neither was the amount of pollen dispersed per flower or the size of stigmatic loads. There were, however, more pollen tubes, on average, at the lowermost part of the style in controls (10.8 tubes/style) than in bractless shrubs (8.3 tubes/style). Small, nonsignificant declines in average seed size, germinability, and seedling mass were detected following bract removal. Data support the notion that bracts are not essential to seed production in mature, relatively dense Lavandula populations where bee pollinators are often in good supply, but may be all-important if plant density is extremely low, or during population establishment. The role of an amplified display in increasing average pollination distance and progeny quality in this species is discussed.
\end{abstract}

Key words: fecundity; floral display; Lavandula; Lamiaceae; Mediterranean; outcrossing; pollinator attraction.

\section{INTRODUCTION}

Many aspects of animal-pollinated plant reproduction are influenced by the size of the floral display, including visitation rates and fecundity (e.g., Willson and Price 1977, Lack 1982, Gori 1983, Cruzan et al. 1988, Galen 1989), outcrossing levels (Geber 1985, Robertson 1992, Klinkhamer et al. 1994), success as a male (Bell 1985, Stanton et al. 1986, Cruzan et al. 1988, Campbell et al. 1991, Devlin et al. 1992, among others), and pollen discounting (Harder and Barrett 1995). Whenever large displays arise from the presentation of many flowers, consequences may also include adjustment to varying resource levels and the opportunity for selective embryo abortion (Sutherland 1986; see Stephenson 1981, and Casper and Niesenbaum 1993 for reviews).

Either by making use of flower polymorphisms (Solomon 1987, Galen and Stanton 1989, Campbell et al. 1991, Stanton et al. 1991, for example) or by manipulating attractive flower parts (Bell 1985, Young and Stanton 1990), most studies on the effects of increased floral displays on plant reproduction consider the individual flower as the attractive unit (see, however, Cruzan et al. 1988, Andersson 1991, Andersson and Widen 1993). Nevertheless, in many angiosperm groups the flowers are reduced in size and aggregated into head-like inflorescences that act as units of at-

Manuscript received 13 July 1995; revised 2 May 1996; accepted 7 May 1996; final version received 30 May 1996. traction. Leaving aside the examples in which inflorescence attractiveness relies on flowers larger than average (for example, in the Compositae), conspicuous secondary structures associated with flowers but not composed of flowers themselves are exceedingly common in several plant families (e.g., the colored bracts of many Araceae, Bromeliaceae, Euphorbiaceae, and Nyctaginaceae; Heywood 1978).

Nonfloral showy structures are tacitly accepted to improve pollination success by enhancing visual display. However, empirical data on this issue are scarce (but see Mendez and Obeso 1992), which is surprising since manipulating such structures is far easier than inducing changes in every flower of an individual. Furthermore, a major difference between floral and nonfloral structures is that the latter can often be relatively free from the strong phylogenetic constraint experienced by most quantitative floral traits (e.g., Webb 1984). Therefore, because nonfloral devices are likely to be evolutionarily more versatile, such organs may provide a useful tool for the study of the relationship between floral display and plant reproduction. In addition, ancillary structures increase showiness without increasing gametophyte numbers (as opposed to producing large numbers of flowers), and the effect of display on visitation rates, phenotypic gender, and outcrossing levels can be tested without the confounding effects of direct sexual allocation.

The purpose of this study was to investigate the presumed advantage of having nonfloral, colored struc- 


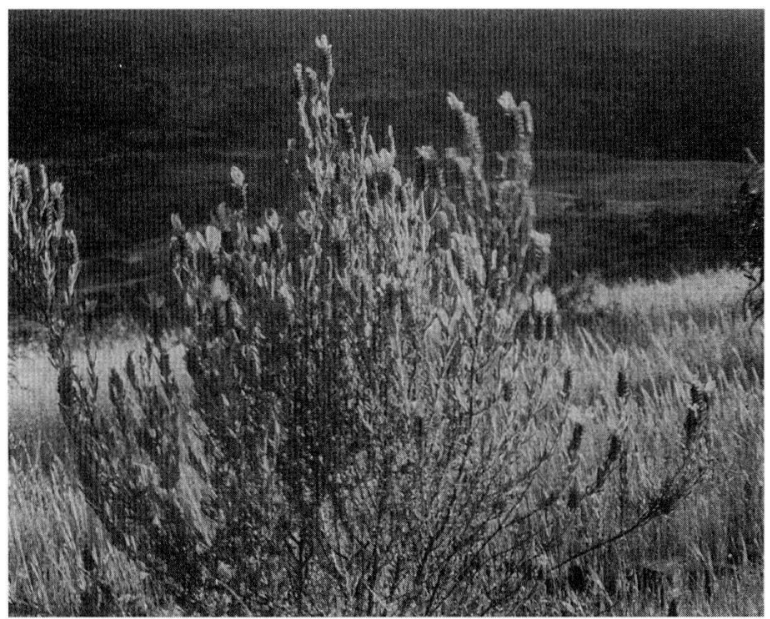

Plate 1. A medium-sized, $\approx 1 \mathrm{~m}$ high Lavandula shrub.

tures (bracts) associated with the flowers of Lavandula stoechas, a Mediterranean shrub. The trait is relatively free from phylogenetic constraint since, among the seven European species of Lavandula, only L. stoechas and the related $L$. viridis have such bracts (Guinea 1972). Although there is natural variation for the studied characteristic (in the intensity of color, shape, and size of bracts), it is often relatively difficult to quantify, so my approach consisted of manipulative experiments to simulate the appearance of "mutants" (Waser 1983) completely lacking bracts.

Pollinators can perceive these organs as evidenced during pilot, bract-removal experiments at the beginning of this study, when I observed that bees often approached the discarded bracts on the ground. Therefore, the generic question is not the rather obvious "Are bracts attractive to pollinators?" but "How much, and in which way does this trait influence plant reproduction?" The following specific questions are addressed: (1) do bracts increase plant visitation rate?; (2) are bracts critical to the number of pollen grains deposited on the stigma and/or the number of pollen tubes in the style?; (3) is the rate of pollen export affected by the presence of bracts?; (4) do bracts increase fecundity?; and (5) is there any difference in vigor among the progenies of normal and bractless plants?

\section{Methods \\ Study plant}

Lavandula stoechas L. (Lamiaceae; Lavandula, hereafter) is an aromatic, Mediterranean xerophytic shrub up to $1 \mathrm{~m}$ high, which is very common in well-insolated, dry sites in southern Spain. From sea level to mountain ranges up to $1000 \mathrm{~m}$ above sea level, populations occur as aggregations of shrubs in patches of varying area. Regeneration occurs only from seed (Herrera 1987). Reproductive characteristics previously studied in this species include head architecture (Devesa et al. 1985), breeding system (Muñoz and Devesa
1987), flower and fruit biology (Herrera 1991, 1993), and insect flower choice (Duffield et al. 1993). Flowers have a small ( $5 \mathrm{~mm}$ long), dark-purple tubular corolla inserted into a tubular calyx, and are aggregated in heads. These are composed of tightly packed dichasia (i.e., groups of flowers on a highly reduced branch) attached to a central, common axis (Fig. 1). Each head encloses some 100 buds, although there are seldom more than 20 flowers open simultaneously. Each head is terminated by a tuft of showy pink bracts (Fig. 1), each measuring $20-30 \times 5-10 \mathrm{~mm}$. There are typically four per head, and since an average individual bears 20-50 heads, the total number of bracts on a flowering shrub is large and their visual impact is (at least to humans) considerable.

Lavandula flowers secrete minute $(0.5-1.5 \mu \mathrm{L})$ amounts of sugar-rich $(30-60 \%)$ nectar and have an average pollen: ovule ratio of 1000 . Although flowers set fruit following experimental pollination with pollen from the same individual (and are thus considered selfcompatible; Muñoz and Devesa 1987), autogamy (i.e., within-flower pollination) rarely occurs in nature because of marked protandry. Because many newly open, pollen-shedding flowers customarily coexist with older, female-phase flowers in any shrub, however, withinplant pollination (i.e., geitonogamy) is probably very common.

\section{Study sites}

The study was conducted during the winter and spring of 1992, 1993, 1994, and 1995 at two southern Spanish localities (Doñana and Aznalcazar) separated

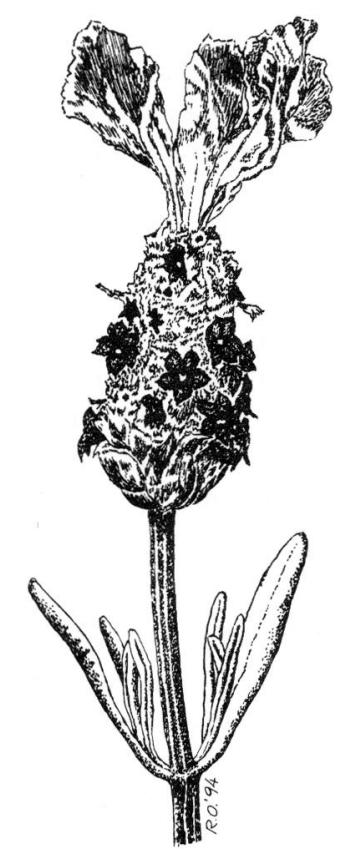

FIG. 1. A head of Lavandula stoechas showing the characteristic group of sterile, colored bracts at the top. 
a
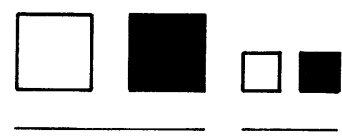

b

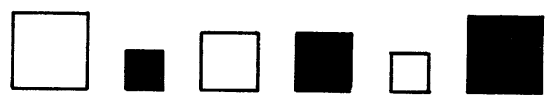

C

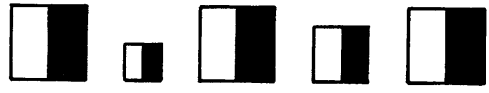

FIG. 2. The three strategies used in this study for spatial interspersion of treatments $(a, b, c)$, with squares representing shrubs, and control/treated experimental units denoted by open/shaded symbols. The varying areas of symbols represent variations in size (head number) among units. Horizontal lines delimit experimental blocks.

by $50 \mathrm{~km}$. The Doñana site is in the Doñana Biological Reserve, a coastal area near the gulf of Cadiz where vegetation is dominated by scrub growing on old stabilized sand dunes (see Rivas-Martinez et al. 1980 for a description). At this site, Lavandula plants grow intermingled with many other shrub species. The Aznalcazar site is further inland but at about the same elevation as the coastal site. This population is a nearly pure stand of Lavandula inhabiting a woodland clearing. The substrate is made up of gravel, and vegetation is largely dominated by Pinus pinea woodland with an understory of xerophytic scrub.

The study populations were selected because of their contrasting spatial structures, shrub size distributions, and pollinator activity regimes. The population at Aznalcazar is composed of some 400 individuals distributed over an area of $20 \times 40 \mathrm{~m}$. Most plants bear 2050 heads when in full bloom (medium-sized shrubs, hereafter), although large plants (50-200 heads) are also common. This is the commonest population structure of Lavandula throughout southern Spain (personal observation). In contrast, the Doñana population is made up of small $(<20$ heads $)$ and medium-sized plants evenly spread over many hectares. Sites also differ in the abundance and diversity of the flower-visiting insect array: at Doñana, Apis mellifera accounts for nearly $90 \%$ of visits (Herrera 1988), whereas at Aznalcazar a varied assemblage of solitary bees is found in addition to honey bees. Furthermore, at the coastal site there are often mild to strong breezes, which negatively affect pollinator activity.

\section{Whole-plant bract removal experiments}

To test the hypothesis that bracts facilitate pollination in Lavandula I selected a sample of plants, removed all the bracts from shrubs chosen at random, and then compared fitness-related variables (e.g., seed set) among individuals with and without bracts. Because the buds from which heads will develop appear synchronously in Lavandula, most bracts in a shrub could be removed at a single date when flowering was about to begin. Additionally, however, I rechecked each treated plant weekly to eliminate bracts from the few residual head buds that could have appeared anew. This "whole-plant approach" was used to study the effects of bracts on insect visitation rates, fecundity, stigmatic pollen loads, and the number of pollen tubes in the style.

Insect visitation rates. - Ten adjacent plants at the Doñana population were selected at the beginning of the 1992 flowering season. Individuals were paired, and heads clipped as necessary from one of the individuals in each pair in order to obtain equal numbers of heads on both plants (Fig. 2a). This number ranged from 36 to 60 heads. A plant within each pair was then selected at random, and all colored bracts were clipped. Paired plants were close enough $(0.5-1 \mathrm{~m})$ to allow simultaneous observation of their visitors following a schedule in which I observed one pair for $4 \mathrm{~min}$, then moved to the next pair for another 4 min, etc., until all five pairs had been monitored. Four such runs were performed on each of two dates, at 1000, 1200, 1400, and 1600 . In all, this accounts for 32 min of observation per pair of shrubs. The same procedure was used at the Aznalcazar population with another set of paired shrubs in which the floral display ranged between 11 and 33 heads/plant. All censusing was carried out in warm, clear weather, which is typical for the blooming period of Lavandula in southern Spain.

Fecundity.-In 1992 and 1994 the fecundity of plants with and without bracts was compared at the Doñana site (Fig. 2b). I was unable to use the same individuals in 1992 and 1994 because of high plant mortality, but plant samples were comparable in that the shrubs inhabited the same area and were similar in size (for the 1992 set, 18 heads/plant on average, range $5-70, N=30$; for the 1994 set, 19 heads/plant, range $5-36, N=20$ ). The method (and timing) used for bract removal was identical to that described previously (see above Whole-plant bract removal experiments).

The main component of fecundity studied was seed set. In Lavandula the ovary has four ovules, and seed set per flower is thus virtually a categorical variable (zero, one, two, three, or four seeds may develop). To get a measure of fecundity statistically more powerful than per-flower seed set, I examined the proportion of ovules within a head that develop into viable seed (i.e., seed set per head). Furthermore, since the loss of flowers (caused by beetles in the genus Meligethes, Nitidulidae) can also be a major determinant of fecundity in Lavandula (Herrera 1993), predator activity was also investigated. A direct measure of predation intensity for heads is difficult to obtain because wilting corollas are dropped from their calyces within 7-10 d from anthesis. However, an estimate can be obtained at the fruiting stage from the proportion of calyces containing insect droppings, cuticles, or chewed flower parts (mostly the ovary). 
Heads are internally heterogeneous because they are in fact aggregations of small, 5-7 flowered units (dichasia). Flowers opening first in each dichasium are most likely to produce fruits, whereas later opening ones are much more resource limited (Herrera 1991). When sampling fruits to assess seed set/head, I used only central (i.e., first-opening) flowers, so fecundity estimates reported below are upper bounds. This was particularly convenient during the 1994 season, when plant fecundity dropped to extremely low levels because of drought. When sampling heads for predation, on the other hand, I used lateral (i.e, later opening) flowers. Since these are preyed upon more intensely than early-opening ones (Herrera 1993), predation rates reported are also maximum estimates. On 4-5 heads per plant, I sampled all (10-15) first-order calyces for viable seeds along with 10 second-order calyces for predation. Sampling different sets of flowers to check fecundity or predation helps to avoid redundancies in the resulting data set and to make these estimates relatively independent. Furthermore, using the same set of flowers to estimate fecundity and predation would have forced me to deal with yet another source of variation (namely within-head heterogeneity) which was of no interest for the study.

Pollen loads and the number of pollen tubes in naturally pollinated flowers.-One way in which bracts might enhance pollination is by increasing the number of times a flower is visited, thus resulting in larger stigmatic pollen loads and/or greater pollen tube number per flower. To test this, 20 small shrubs about to flower were marked at Doñana during the 1994 season and every colored bract removed from 10 of these plants. Shrubs were spread over an area of $900 \mathrm{~m}^{2}$ and intermingled with many nonexperimental individuals (see Fig. 2b). At weekly intervals on three different dates, dry corollas (and the styles therein) that remained attached to the calyx were haphazardly collected from a number of heads on each shrub and fixed in formaline: acetic acid: alcohol (5:5:90). Material from each shrub was thoroughly mixed (pollen was firmly adhered to stigmas, so grain exchange between stigmas was unlikely). Then a sample of 10 styles was chosen at random. After clearing with hot, $8 \mathrm{~mol} / \mathrm{L}$ $\mathrm{NaOH}$ for 30 min, styles were rinsed, stained in a drop of decolorized aniline-blue, and observed under UV light (Martin 1959) to count the number of pollen grains adhered to the stigma and of pollen tubes at the base of the style.

\section{Split-plant bract removal}

Using shrubs as experimental units to perform bract removal allows one to directly assess the trait's significance for fitness. However, extensive between-plant variation existed for every studied variable, which might generate inconclusive results if the hypothesized effect was relatively weak. To allow some control of between-plant variation, I also used half-shrubs as ex- perimental units in a separate set of experiments. In these, I selected a group of plants, then split each plant into two equal-sized halves (i.e., with the same number of heads on each side), and compared response variables within and among plants following bract removal from one randomly chosen half (see Fig. 2c). Plant splitting was done by clipping heads so as to create a $10-20 \mathrm{~cm}$ wide strip devoid of flowers across the shrub. In this way, I studied the potential effects of bracts on pollinator choice, number of heads visited, amount of pollen exported by individual flowers, as well as seed and seedling characteristics. As in the whole-plant approach, bracts were removed from heads before the onset of the blooming season.

A disadvantage of using split plants as experimental units is that treatment effects are not directly interpretable in terms of fitness (since half-plants are not real entities but artifices), and one has to conjecture about how and if results from half-shrubs located side by side would extrapolate to actual shrubs. At least regarding interplant distances and its bearing on pollinator attraction, this is not a serious drawback because true individuals are most often side by side in Lavandula populations, and pollinators are thus likely to ditsplay similar flight patterns, regardless of the fact that they face a pair of real shrubs or a pair of experimentally produced half-shrubs. There could be some doubt, however, on whether half-shrubs share resources: if there existed compensatory effects within a split shrub, bract removal effects in (for example) seed size might be obscured. The available evidence, however, indicates that such effects are unlikely to occur. For example, the low fruit set that characterizes late-opening flowers within a head can be artifficially increased by removing a subset of flowers from the head (Muñoz and Devesa 1987), but it cannot be by removing other heads on the shrub (Herrera 1991). This supports the idea that Lavandula heads behave like independent resource allocation units, and that compensatory effects within split shrubs are not likely.

Pollinator choice.-During the 1993 season, 10 plants per population were selected and split as described above. The resulting halves were sequentially observed during $30-\mathrm{min}$ periods to a total of $120 \mathrm{~min}$ per plant (i.e., a total of $1200 \mathrm{~min}$ of observation/population) to record the number of insects that, when approaching a split shrub for the first time, selected the side with bracts or the side without bracts. This was intended to emphasize the effect of bracts on insect choice at a distance (i.e., attention was not paid to shifts from the first-chosen half-plant to the neighboring one). The numbers of heads on half-shrubs ranged between 10 and 60 at Doñana (mean $\pm 1 \mathrm{SE}, 32.0 \pm 2, N=$ 20), and between 14 and 55 at Aznalcazar (34.7 \pm 4 , $N=20$ ). Observations were carried out from morning to afternoon on different dates at each of the populations.

Number of heads visited.-Increased conspicuous- 
ness brought about by bracts might help shrubs to retain visitors for a longer period of time, which might result in more flowers or heads being visited by each pollinator. This might in turn affect the female and/or the male component of reproduction (by increasing either stigmatic pollen loads and/or pollen export). The number of heads visited by pollinators was investigated at Aznalcazar by selecting three large shrubs, splitting each into halves as described above, and then removing bracts from one half. When an insect arrived, I noted how many heads it visited before leaving that half. To account for pollinator-specific effects, separate records were kept for Apis mellifera and solitary bees. Overall, 188 insects were tracked.

Pollen dispersal.-Bracts could have no apparent effect on fecundity, and yet have a positive effect on the male component of reproduction. To check this possibility, 405 flower buds about to open were marked early in the morning on March 1995 at the Doñana population from a total of 20 previously split shrubs (data were partially missing for one of the shrubs, whereas another plant happened to be male sterile, so the final sample size was only 18 individuals). Of these buds, 61 were on heads bagged with $0.2-\mathrm{mm}$ mesh that excluded all kind of pollinators, whereas the remaining (on heads with or without bracts) were exposed to insects. Flowers were left to open and be visited normally during their 1 st $\mathrm{d}$ of anthesis, at the end of which a sample of corollas was picked up with great care to avoid any pollen losses and individually kept in numbered vials. The remaining flowers were left exposed to pollinators during the 2 nd $\mathrm{d}$ of anthesis and then collected. All four anthers of flowers are open at the time of anthesis in Lavandula, and pollen has lost most viability after $48 \mathrm{~h}$ of release from anthers (Muñoz and Devesa 1987).

The amount of pollen remaining in the anthers in all three groups of flowers (bagged, exposed for $1 \mathrm{~d}$, and exposed for $2 \mathrm{~d}$ ) was estimated by adding $0.2 \mathrm{~mL}$ of a water-detergent-safranine solution to each vial, carefully squashing the anthers with forceps, and taking two $0.5-\mu \mathrm{L}$ aliquots of the solution. The number of grains in each aliquot was then counted at $40 \times$ under the microscope. Because the numbers in the first and the second extraction for each flower were highly correlated $(r=0.960, N=405, P \ll 0.001)$, these were averaged and, after correcting for the dilution factor, the resulting figure was used as an estimate of the pollen that each flower had failed to disperse. Weather conditions were similar during the $2 \mathrm{~d}$ spanned by the experiment, with light breezes, warm temperatures (daily maxima $\approx 25^{\circ} \mathrm{C}$ ), and moderate to high bee activity.

Seed and seedling characteristics.-To investigate the effect of bracts on seed characteristics, seven shrubs at Doñana were split as previously described at the onset of the 1993 blooming season. By the time the fruits were ripe (early summer) heads from each half-

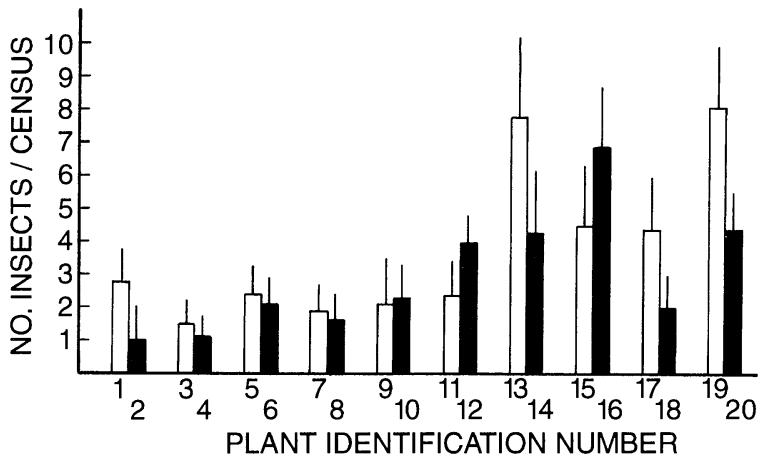

FIG. 3. Visitation rates to paired Lavandula shrubs (control/no bracts) matched by size. Each bar is the mean number of pollinators arriving at a shrub per 4-min census $(N=8$ for each plant). Open bars represent controls, and shaded bars represent treated shrubs. Vertical lines span 2 SE. Plants 110 are from Doñana, 11-20 are from Aznalcazar.

plant were harvested, taken to the laboratory, and stored at ambient temperature. The next autumn, seeds from early-opening flowers (i.e., those experiencing less abortion) were picked, and those unfilled or showing signs of predation discarded. A total of 526 randomly chosen seeds were individually weighed to the nearest $0.01 \mathrm{mg}$ to test for the effect of bract removal on seed size. This experiment was repeated in 1995 , this time using 18 different shrubs.

Doñana plants were rather small, thus making it difficult to collect large numbers of seeds. Therefore, the effect of bract removal on germination rate and seedling size was studied in five large shrubs from Aznalcazar. Three-hundred seeds from each half-plant were sown in pots containing moist peat inside an unheated glasshouse (three pots per half-plant, 100 seeds per pot), and the number of seedlings appearing in each pot recorded 2 wk later. Seedlings were thinned to 20 per pot at this time, and those remaining were regularly watered for the next $30 \mathrm{~d}$. At this point I harvested the seedlings and determined their fresh masses to the nearest milligram.

\section{Data analyses}

Experimental units in this study are either whole shrubs or half-shrubs (see Fig. 2) and, accordingly, variates for the studied variables are averages for either plants or half-plants. For example, when looking at visitation rates to shrubs with or without bracts, the numbers of insects per 4-min census for a given plant were averaged and the resulting figure used. If what was being addressed was the effect on (for example) pollen export, the number of grains left in several flowers within a half-plant were averaged and the mean used to represent this half-plant's rate of failure in pollen export. In general, means distributed normally and no transformations were needed, with the exception of percentage seed set, which was arcsine square-root transformed. When appropriate (i.e., the designs in Fig. 
TABLE 1. (A) Relationship of colored bracts and fecundity in Lavandula. The analysis of covariance (B) used the averaged seed set of five heads per shrub as the response variable, and average predation intensity as a continuous covariate. "Treatment" refers to bract removal. The experimental design corresponds to that shown in Fig. $2 \mathrm{~b}$.

\begin{tabular}{llcccc}
\hline \hline A) & & \multicolumn{5}{c}{ Seed set of shrubs $(\%) \dagger$} \\
\cline { 3 - 6 } & & $\begin{array}{c}\text { With bracts } \\
(\bar{X} \pm 1 \text { SE })\end{array}$ & $\begin{array}{r}\text { Without bracts } \\
(\bar{X} \pm 1 \text { SE })\end{array}$ \\
Year & & $49 \pm 5$ & & $55 \pm 5$ \\
1992 & & $21 \pm 4$ & $14 \pm 4$ \\
1994 & & & & & \\
B) & & df & MS & $F$ & $P$ \\
Year & Source & 1 & 277.5 & 0.78 & 0.39 \\
\hline 1992 & Treatment & 1 & 15.6 & 0.04 & 0.84 \\
& Predation & 27 & 355.4 & & \\
& Error & 1 & 82.9 & 0.69 & 0.42 \\
1994 & Treatment & 1 & 546.6 & 4.55 & 0.04 \\
& Predation & 17 & 120.0 & & \\
& Error & 17 &
\end{tabular}

$\dagger N=10$ in all cases except for 1992 (with bracts), where $N=14$.

$2 \mathrm{a}, \mathrm{c})$, pairs of experimental units were treated as randomized blocks. Analyses were performed with procedures in SAS (1990) and SYSTAT (Wilkinson 1986) statistical packages.

\section{RESULTS}

\section{Whole-plant experiments: insect visitation rates}

At the sparser population shrubs received from 1 to 3 insects/census, whereas at the densest site between 2 and 8 insects/census were recorded (Fig. 3). The rates of visitation for pairs of control and treated shrubs correlated positively $\left(r_{s}=0.650, N=10, P<0.05\right)$, indicating that among-plant variations are due (at least in part) to spatial location and head number.

A randomized block analysis of plant means revealed a significant effect of "Block" (i.e., shrub pair; $\mathrm{MS}=$ 0.561 , df $=9, F=3.64, P=0.03$ ), while it failed to detect any effect due to bracts (MS $=0.299$, df $=1, F$ $=1.95, P=0.20$; error MS $=0.154, \mathrm{df}=9)$. Because of high among-plant variation in visitation rates, however, this analysis is prone to Type II error. With the observed variance in visitation rates and $N=10$, the power of a test for differences among treatment means is only 0.67 (i.e., a true difference would fail to be detected at $P<0.05$ in $33 \%$ of tests). Overall, bractless shrubs received $2.9 \pm 0.6$ pollinators/census, as opposed to $3.8 \pm 0.8$ received by controls (i.e., a $23 \%$ decrease).

\section{Fecundity}

Average overall seed set was $\approx 50 \%$ in 1992 , and as low as $15 \%$ in 1994. Drought during 1994 may (in addition to plant identity) account for the difference (Table 1). In 1992 seed set was higher in treated shrubs than in controls, and the reverse occurred in 1994

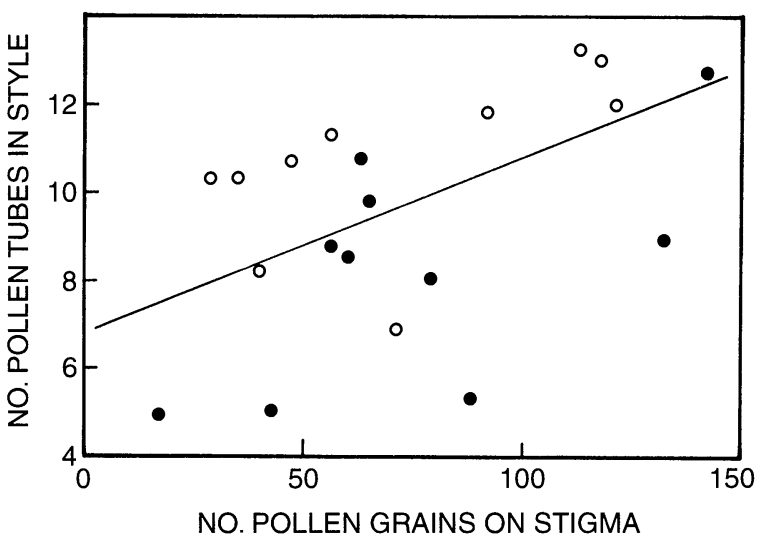

FIG. 4. The relationship between pollen load on the stigma and the number of tubes in the style in Lavandula. Each dot is the average value for a shrub with $(\bigcirc)$ or without $(O)$ bracts. The regression line for this relationship (tubes $=6.8$ \pm 0.04 stigmatic load, $r^{2}=0.27, N=20$ ) is also shown.

However, in no year were treatment effects significant (Table 1). The covariate proved significant only during 1994, implying that fecundity and flower predation correlated (negatively) during that year.

\section{Pollen loads and number of tubes as affected by bracts}

Overall, there were, on average, $74 \pm 5$ pollen grains per stigma (median 52, minimum 0, maximum 400) and $9.5 \pm 0.5$ pollen tubes per style (median 10 , minimum 0, maximum 24) in the studied sample. The average pollen grain: pollen tube ratio was 7.8 , and that of pollen tubes to ovules 2.4 . Of 200 flowers analyzed, only six had no pollen on their stigmas.

Plant means for the size of stigmatic pollen loads ranged from 16.8 to 141.5 grains, and the number of

TABLE 2. (A) Relationship of Lavandula bracts and the number of pollen tubes that reach the lowermost part of the style. The analysis of covariance (B) used the average number of tubes in 10 naturally pollinated flowers per shrub as the response variable, and the average number of pollen grains on the stigma as a continuous covariate. "Treatment" refers to bract removal. The experimental design corresponds to that shown in Fig. $2 b$.

A)

\begin{tabular}{llc} 
& \multicolumn{2}{c}{ Shrubs $\dagger$} \\
\cline { 2 - 3 } \multicolumn{1}{c}{ Variable } & With bracts & Without bracts \\
& $(\bar{X} \pm 1 \mathrm{SE})$ & $(\bar{X} \pm 1 \mathrm{SE})$ \\
\hline Pollen grains on stigma & $73.2 \pm 12$ & $74.6 \pm 12$ \\
Pollen tubes in style & $10.8 \pm 1$ & $8.3 \pm 1$
\end{tabular}

B)

\begin{tabular}{lrccc}
\multicolumn{1}{c}{ Source } & df & MS & $F$ & $P$ \\
\hline Treatment & 1 & 32.7 & 9.23 & 0.007 \\
Pollen load & 1 & 35.8 & 10.090 & 0.006 \\
Error & 17 & 3.6 & &
\end{tabular}

$\dagger N=10$ in all cases except for pollen grains on stigma (without bracts), where $N=16$. 
TABLE 3. (A) Pollinator behavior as affected by colored bracts and (B) analysis of variance. The approaching rate is the average number of insects, which, when arriving to a split (bract/no bracts) shrub from a distance, chose either the control or the treated half. The experimental design corresponds to that shown in Fig. 2c, with each split shrub representing a block.

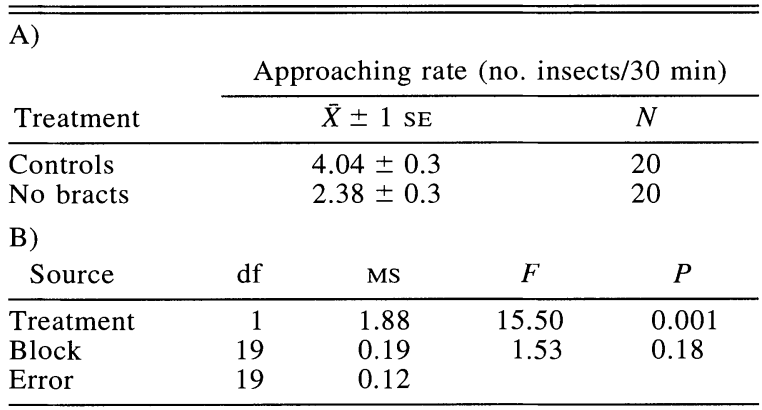

pollen tubes in the style varied between 4.9 and 13.2. It is worthwhile noting that pollen tube number was less variable among plants $(\mathrm{CV}=27 \%)$ than stigmatic pollen loads $(\mathrm{CV}=50 \%)$. Thus, pollen deposition on the stigma was heavily affected-by factors related to plant identity, whereas the potential for ovule fertilization was relatively free from constraint by individual-specific traits (see Discussion).

A significant, positive linear relationship between pollen tube number and stigmatic pollen load was detected (Fig. $4 ; F=6.69$, df $=1,18, P=0.02$ ). Because shrubs without bracts appear mostly below the line of regression, this relationship seems to be affected by bract removal. This is confirmed by analysis of covariance (Table 2). Average pollen tube number depends not only on the number of pollen grains on the stigma, but also on the presence or absence of bracts. On average, bract removal decreased the number of pollen tubes in the style by $23 \%$ (Table 2 ).

\section{Split-plant experiments: pollinator selection of plant halves}

Plant halves with bracts did better at getting distant (from any other shrub) pollinator approaches than halves without bracts (Table 3), since bract removal was associated with a $41 \%$ decrease in average approaching rate. Furthermore, and because plant identities (i.e., factor "Block") did not explain a significant part of variation (Table 3), treatment effects occurred with independence of shrub size and at both the dense and the sparse study sites.

\section{Number of heads visited}

Apis mellifera probed $5.7 \pm 0.9$ heads $(N=30)$ on controls, vs. $5.5 \pm 0.8(N=30)$ on treated half-shrubs without bracts $(T=0.14, \mathrm{df}=58, P=0.8)$. For solitary bees, means were, respectively, $3.1 \pm 0.4(N=53)$ and $3.7 \pm 0.5(N=55 ; T=0.85$, df $=106, P=0.4)$. Departure decisions were therefore independent of the presence of bracts in both major pollinator groups.

\section{Bracts and pollen dispersal}

Of the 4000 pollen grains produced by each Lavandula flower (as estimated in the bud stage), $57 \%$ were dispersed during the 1 st $d$ of anthesis, whereas, on average, $17 \%$ remained in the anthers at the end of the 2nd d (Table 4). There were no significant treatment effects on the amount of pollen left undispersed. A highly significant effect was detected for the "Block" factor, however, implying that certain shrubs dispersed pollen much more efficiently than others. The significant Block $\times$ Time interaction reveals that individual efficiencies in dispersing pollen may vary from one day to the next.

\section{Seed and seedling characteristics}

The masses of seeds produced in half-shrubs without bracts were, on average, smaller than those of controls in both 1993 and 1995 (Table 5). However, the differences were minimal $(\approx 0.02 \mathrm{mg}$ ), and there were no significant treatment effects for any of the years (statistical power is 0.95 and 0.83 , respectively, for 1992 and 1995). Percentage seed germination was also statistically undistinguishable in treated and control halfplants (power equals 0.95).

Greenhouse-grown seedlings ( $30 \mathrm{~d}$ old) from treated half-shrubs were significantly smaller than those of controls in two out of five cases (Fig. 5). There were, however, no overall significant treatment $(\mathrm{MS}=300$, $\mathrm{df}=1, F=1.9, P=0.24)$ or block (MS $=323, \mathrm{df}=$ $4, F=2.1, P=0.25$; error $\mathrm{MS}=155$, df $=4$ ) effects. Again, this analysis is prone to Type II error, with

TABLE 4. (A) Bracts and pollen export in Lavandula shrubs split into halves (bracts/no bracts). The average numbers of pollen grains remaining in the anthers of 10 flowers per half-shrub at the end of the first and second day of anthesis were subject to a repeated-measures analysis (B), with split shrubs representing blocks (see Fig. 2c).

A)

\begin{tabular}{ccc} 
& \multicolumn{2}{c}{$\begin{array}{c}\text { Undispersed pollen grains } \dagger \\
\text { per flower on half-shrubs }\end{array}$} \\
\cline { 2 - 3 } Day of & With bracts & Without bracts \\
anthesis & $(\bar{X} \pm 1$ SE $)$ & $(\bar{X} \pm 1$ SE $)$ \\
\hline First & $1763 \pm 245$ & $1698 \pm 231$ \\
Second & $725 \pm 75$ & $662 \pm 60$
\end{tabular}

B) Repeated-measures analysis

\begin{tabular}{lrrrc}
\multicolumn{1}{c}{ Source } & df & \multicolumn{1}{c}{ MS } & \multicolumn{1}{c}{$F$} & $P$ \\
\hline Between subjects & & & & \\
$\quad$ Treatment & 1 & 73578 & 0.36 & 0.55 \\
Block & 17 & 1121702 & 5.51 & $<0.001$ \\
Error & 17 & 203668 & & \\
Within subjects & & & & \\
Time & 1 & 19333151 & 129.3 & $<0.001$ \\
Time $\times$ Treatment & 1 & 14 & 0.0 & 0.9 \\
Time $\times$ Block & 17 & 797423 & 5.3 & $<0.001$ \\
Error (Time) & 17 & 149462 & &
\end{tabular}

$\dagger$ Control flowers not exposed to pollinators retained 3275 \pm 254 grains. $N=18$ in all cases. 
TABLE 5. (A) Characteristics of the seeds and seedlings from Lavandula half-shrubs. In the ANOVAs (B), "Treatment"' refers to bract removal, and blocks are split shrubs.

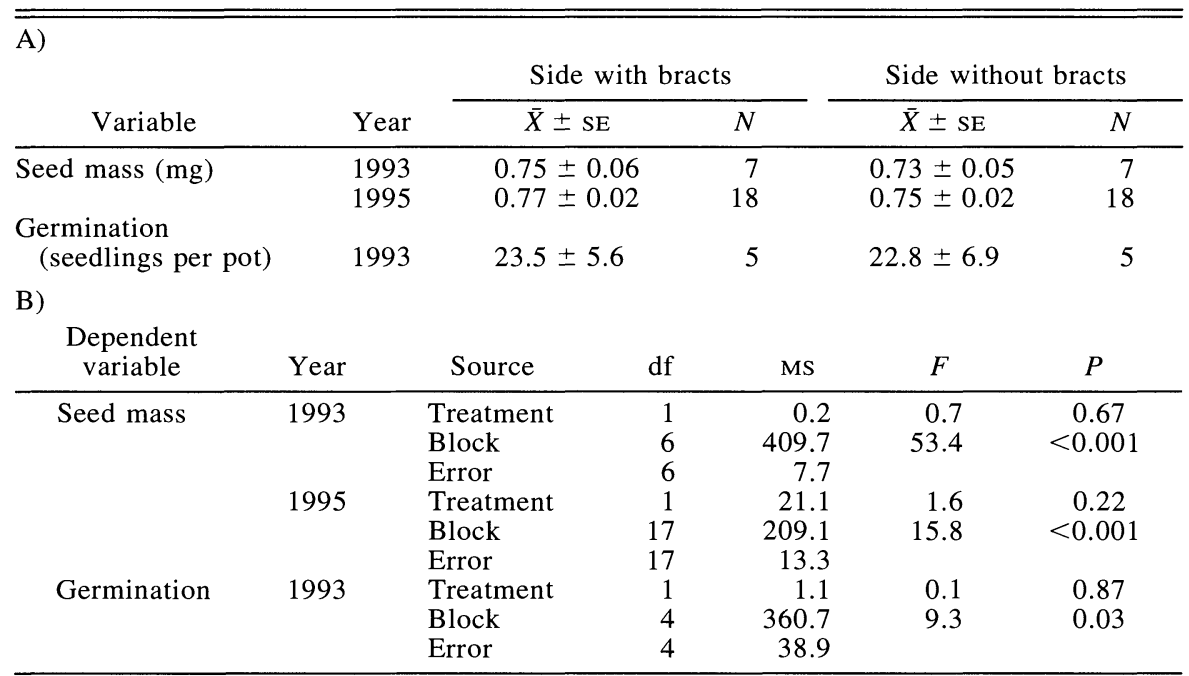

statistical power being only 0.72 . Overall seedling mass was $86.2 \pm 7.9 \mathrm{mg}$ for controls, and $75.2 \pm 5.8 \mathrm{mg}$ for treated half-shrubs.

\section{Discussion}

\section{Visitation rates}

Mean insect visitation rate decreased by $23 \%$ in bractless shrubs as compared to controls, so the answer to the first question addressed (do Lavandula bracts enhance visitation?) must be yes. This is in agreement with previous reports on the relationship between plant advertisement and pollinator visitation (Willson and Price 1977, Augspurger 1980, Thomson 1981, Gori 1983, Waser 1983, Schemske and Ågren 1995). Nevertheless, differences in this study were not great

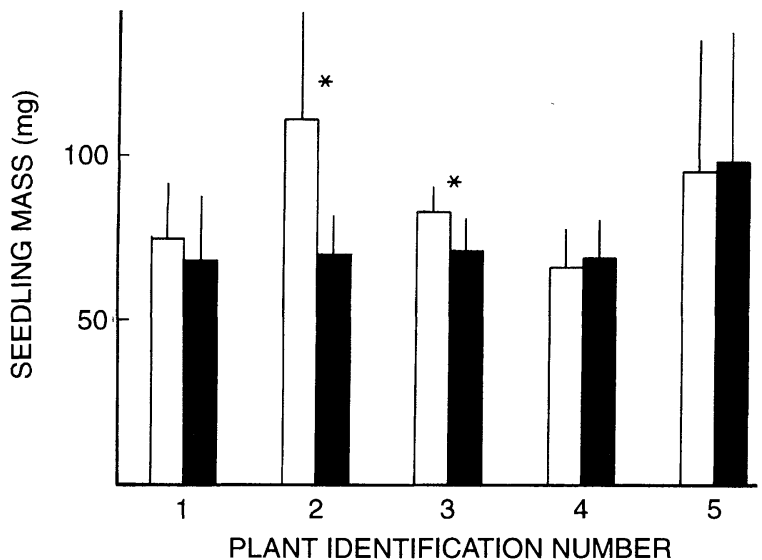

FIG. 5. Mean seedling sizes from split (bracts/no bracts) Lavandula shrubs. Open bars are control, and shaded bars are treated half-shrubs. Vertical lines span 2 SE. Means significantly different at $P<0.05$ are marked with an asterisk (Student's test). Plants 1-5 are from Aznalcazar. enough to reach statistical significance, which could be considered just an unwelcome aftermath of extensive among-plant variance and subsequent low statistical power of tests or, alternatively, might be evidence that the (otherwise hardly questionable) positive effect of display on pollinator visitation need not be straightforward. It can be noticeably obscured if, for example, insects remember the locations of specific shrubs from days previous to the experiment and their behavior becomes thus in part independent of display (Janzen 1971, Heinrich 1976, Eickwort and Ginsberg 1980, Thomson 1988). Additionally, and simply because of nearest-neighbor foraging (Levin and Kerster 1969, Waddington 1983), control shrubs with bracts probably "passed" visitors to its bractless counterparts, which may also have resulted into attenuated differences. The overwhelming effect of bracts on pollinator choice demonstrated in split-shrub experiments, on the other hand, suggests that these organs may be extremely useful to shrubs that need to be approached from a distance (e.g., during early population establishment stages).

\section{Pollination intensity and pollen-tube numbers}

Bracts are not critical to the number of pollen grains adhered to the stigma, but they are to the number of tubes in the style. There are not many reports on the size of microgametophyte populations within pistils of naturally pollinated flowers, but considerable interplant variation has been shown on occasions (Levin 1990, Niesenbaum 1994). In Lavandula, variance in mean stigmatic loads was comparable to that of pollinator visitation rates $(\mathrm{CV}=50$ and $63 \%$, respectively), whereas tube number per style was more constant $(\mathrm{CV}$ $=27 \%$ ). The proximate cause for this relative lack of variation is probably that the tiny transmitting tissues $(0.2-0.3 \mathrm{~mm}$ in diameter) inside styles were unable to 
accommodate vast numbers of tubes, and styles contained as many tubes as they could hold. Judging from microscopic observations, there was virtually no free space in styles containing 20-24 tubes, which probably represents an upper limit for this species.

At present I can only speculate on why styles from bractless shrubs have fewer tubes than controls in spite of equivalent stigmatic pollen loads. A possible explanation is that bract removal disrupted a hypothetically optimal crossing distance (Waser and Price 1983, 1991, Dudash 1990). Partial support for this idea comes from pollinator-choice experiments, in which control halfshrubs received distant pollinator approaches more often than their bractless counterparts. If distant pollen arrives less frequently to bractless shrubs and the growth of tubes from spatially close neighbors is somehow discouraged, there would, on average, be fewer tubes in bractless shrubs. Even a weak rejection of close-neighbor tubes might reduce mean tube number in this way, but the existence of such a mechanism remains to be demonstrated.

\section{Male function}

Pollen produced per flower is in Lavandula relatively scant (4000 grains, $83 \%$ of which was dispersed at the end of the 2 nd d of anthesis). Furthermore, pollinators probed the same number of heads on control and bractless half-shrubs, and this made changes in per-flower visitation rates unlikely (a precondition for increased pollen export; Stanton et al. 1986, Cruzan et al. 1988, Young and Stanton 1990). Accordingly, the average rate of pollen export was unaltered by bract removal and the hypothesized effect of increased display on the success as a male must be rejected (question 3 ). Obviously, over distances as short as plant diameter $(0.3-$ $0.6 \mathrm{~m}$ ) corollas provide enough advertisement, and heads are not missed by pollinators even if they lack bracts.

\section{Fecundity and progeny quality}

Bract removal had no significant effects on the fecundity of individual Lavandula shrubs. Little or no change in seed production following experimental manipulations of advertisement intensity are not uncommon (Waser 1979, Andersson 1991, Mendez and Obeso 1992) and, at least in Lavandula, this probably stems from fruit production being more resource than pollen limited. For example, the abortion rate of late-opening flowers can be reduced by removing developing ovaries on the same head (Muñoz and Devesa 1987), and artificially fertilized shrubs increase their fecundities relative to unfertilized controls (J. Herrera, unpublished data). However, this is not to say that bracts are generally useless in this respect, only that shrubs in the studied populations were to some extent overadvertised.

Within-shrub differences among bractless and control half-plants regarding the vigor of the progeny were significant (and in the expected direction if bracts increased seed quality; question 5) only in two out of five cases. Overall, the effect on progeny quality was nonsignificant, but these kinds of repercussions can be hard to demonstrate in Lavandula because of extensive variation between shrubs and ensuing high rate of Type II error. Sowing the seeds in the field instead of the greenhouse may amplify differences (e.g., Dudash 1990, Montalvo 1994), but it is obvious that a genetic approach would help to get a better knowledge of this issue.

Therefore, the last question addressed at the beginning of this study (i.e., do bracts contribute to increased progeny vigor?) cannot be unambiguously answered with the available data. Since there were fewer pollen tubes within styles of bractless shrubs, however, and because tube number has a number of implications on progeny development (e.g., through microgametophyte competition, Hill and Lord 1986, Snow 1986, Mulcahy et al. 1983; and/or through female choice at either preor postzygotic stages, Stephenson and Bertin 1983, Marshall and Folsom 1991, Snow 1994, for example), there is circumstancial evidence that increased advertisement provided by bracts can make a contribution to fitness even in mature, relatively dense populations with more than adequate pollinator service.

\section{ACKNOWLEDGMENTS}

This study benefited from conversations with many people about the role of bracts in Lavandula. Thanks are particularly due to Antonio Rodriguez-Sierra for his enthusiastic help during field work, and to Ramona Ortega for drawing Fig. 1. The author greatly acknowledges C. M. Herrera, P. G. L. Klinkhamer, N. M. Waser, and an anonymous reviewer for constructive comments on a previous version of the manuscript. The Estación Biológica de Doñana provided permission to work in the Reserve, and the Spanish Junta de Andalucía gave financial support through grant 4086 of the Programa de Ayuda a los Grupos de Investigación.

\section{Literature Cited}

Andersson, S. 1991. Floral display and pollination success in Achillea ptarmica (Asteraceae). Holarctic Ecology 14: 186-191.

Andersson, S., and B. Widen. 1993. Pollinator-mediated selection on floral traits in a synthetic population of Senecio integrifolius (Asteraceae). Oikos 66:72-79.

Augspurger, C. K. 1980. Mass-flowering of a tropical shrub (Hybanthus prunifolius): influence on pollinator attraction and movement. Evolution 34:475-488.

Bell, G. 1985. On the function of flowers. Proceedings of the Royal Society of London, Series B, Biological Sciences 223:224-265.

Campbell, D. R., N. M. Waser, M. V. Price, E. Lynch, and R. J. Mitchell. 1991. Components of phenotypic selection-pollen export and flower corolla width in Ipomopsis aggregata. Evolution 45:1458-1467.

Casper, B. B., and R. A. Niesenbaum. 1993. Pollen versus resource limitation of seed production: a reconsideration. Current Science 65:210-214.

Cruzan, M. B., P. R. Neal, and M. F. Willson. 1988. Floral display in Phyla incisa-consequences for male and female reproductive success. Evolution 42:505-515.

Devesa, J. A., J. Arroyo, and J. Herrera. 1985. Contribución 
al conocimiento de la biología floral-del género Lavandula L. Anales Jardin Botanico Madrid 42:165-186.

Devlin, B., J. Clegg, and N. C. Ellstrand. 1992. The effect of flower production on male reproductive success in wild radish populations. Evolution 46:1030-1042.

Dudash, M. R. 1990. Relative fitness of selfed and outcrossed progeny in a self-compatible, protandrous species, Sabatia angularis L. (Gentianaceae): a comparison in three environments. Evolution 44:1129-1139.

Duffield, G. E., R. C. Gibson, P. M. Gilhooly, A. J. Hess, C. R. Inkley, F. S. Gilbert, and C. J. Barnard. 1993. Choice of flowers by foraging honey bees (Apis mellifera)-possible morphological cues. Ecological Entomology 18:191197.

Eickwort, G. C., and H. S. Ginsberg. 1980. Foraging and mating behavior in Apoidea. Annual Review of Entomology 25:421-446.

Galen, C. 1989. Measuring pollinator-mediated selection on morphometric floral traits: bumblebees and the Alpine Sky Pilot, Polemonium viscosum. Evolution 43:882-890.

Galen, C., and M. L. Stanton. 1989. Bumblebee pollination and floral morphology-factors influencing pollen dispersal in the Alpine Sky Pilot, Polemonium viscosum (Polemoniaceae). American Journal of Botany 76:419-426.

Geber, M. A. 1985. The relationship of plant size to selfpollination in Mertensia ciliata. Ecology 66:762-772.

Gori, D. F. 1983. Post-pollination phenomena and adaptive floral changes. Pages 31-49 in C. E. Jones and R. J. Little, editors. Handbook of experimental pollination biology. Scientific and Academic Editions, New York, New York, USA.

Guinea, E. 1972. Lavandula. Pages 187-188 in T. G. Tutin et al., editors. Flora Europaea. Volume 3. Cambridge University Press, Cambridge, England.

Harder, L. H., and S. C. H. Barrett. 1995. Mating cost of large floral displays in hermaphrodite plants. Nature 373 : $512-514$

Heinrich, B. 1976. The foraging specialization of individual bumblebees. Ecological Monographs 46:105-128.

Herrera, J. 1985. Nectar secretion patterns in southern Spanish mediterranean scrublands. Israel Journal of Botany 34 $47-58$.

- 1987. Flower and fruit biology in southern Spanish mediterranean shrublands. Annals of the Missouri Botanical Garden 74:69-78.

- 1988. Pollination relationships in southern Spanish mediterranean scrublands. Journal of Ecology 76:274-287.

-1991. Allocation of reproductive resources within and among inflorescences of Lavandula stoechas L. (Lamiaceae). American Journal of Botany 78:789-794.

-1993. Blooming dates of individual inflorescences and plants as determinants of flower and fruit predation in Lavandula stoechas (Lamiaceae). Acta Oecologica 14:867874.

Heywood, V. H., editor. 1978. Flowering plants of the world. Oxford University Press, Oxford, England.

Hill, J. P., and E. M. Lord. 1986. Dynamics of pollen tube growth in the wild radish, Raphanus raphanistrum (Brassicaceae). I. Order of fertilization. Evolution 40:13281333

Janzen, D. H. 1971. Euglossine bees as long-distance pollinators of tropical plants. Science 171:203-205.

Klinkhamer, P. G. L., T. J. De Jong, and J. A. J. Metz. 1994. Why plants can be too attractive-a discussion of measures to estimate male fitness. Journal of Ecology 82:191-194.

Lack, A. J. 1982. Competition for pollinators in the ecology of Centaurea scabiosa L. and Centaurea nigra L. Insect visits and the number of successful pollinations. New Phytologist 91:321-339.

Levin, D. A. 1990. Sizes of natural microgametophyte pop- ulations in pistils of Phlox drummondii. American Journal of Botany 77:356-363.

Levin, D. A., and H. W. Kerster. 1969. The dependence of bee-mediated pollen and gene dispersal upon plant density. Evolution 23:560-571.

Marshall, D. L., and M. W. Folsom. 1991. Mate choice in plants-an anatomical to population perspective. Annual Review of Ecology and Systematics 22:37-63.

Martin, F. W. 1959. Staining and observing pollen tubes in the style by means of fluorescence. Stain Technology 34: $125-128$.

Mendez, M., and J. R. Obeso. 1992. Influencia del osmóforo en la infrutescencia en Arum italicum Miller (Araceae). Anales Jardin Botanico Madrid 50:229-237.

Montalvo, A. M. 1994. Inbreeding depression and maternal effects in Aquilegia caerulea, a partially selfing plant. Ecology 75:2395-2409.

Mulcahy, D. L., P. S. Curtis, and A. A. Snow. 1983. Pollen competition in a a natural population. Pages 330-337 in C. E. Jones amd R. J. Little, editors. Handbook of experimental pollination biology. Scientific and Academic Editions, New York, New York, USA.

Muñoz, A., and J. A. Devesa. 1987. Contribucion al conocimiento de la biologia floral del genero Lavandula L. II. Lavandula stoechas L. subsp. stoechas. Anales Jardin Botanico Madrid 44:63-78.

Niesenbaum, R. A. 1994. Spatial and temporal variation in pollen tube numbers in Lindera benzoin (Spicebush). Canadian Journal of Botany 72:268-271.

Rivas-Martínez, S., M. Costa, S. Castroviejo, and E. Valdés. 1980. Vegetación de Doñana (Huelva, España). Lazaroa 2: 5-189.

Robertson, A. W. 1992. The relationship between floral display size, pollen carryover and geitonogamy in Myosotis colensoi (Kirk) Macbride (Boraginaceae). Biological Journal of the Linnean Society 46:333-349.

SAS. 1990. SAS/STAT user's guide. Version 6. Fourth edition. SAS Institute, Cary, North Carolina, USA.

Schemske, D. W., and J. Ågren. 1995. Deceit pollination and selection on female flower size in Begonia involucrata: an experimental approach. Evolution 49:207-214.

Snow, A. A. 1986. Pollination dynamics of Epilobium canum (Onagraceae): consequences for gametophytic selection. American Journal of Botany 73:139-151.

-1994. Postpollination selection and male fitness in plants. American Naturalist 144:S69-S83.

Solomon, B. P. 1987. The role of male flowers in Solanum carolinense-pollen donors or pollinator attractors? Evolutionary Trends in Plants 1:89-93.

Stanton M., A. A. Snow, and S. N. Handel. 1986. Floral evolution: attractiveness to pollinators increases male fitness. Science 232:1625-1627.

Stanton, M., H. J. Young, N. C. Ellstrand, and J. M. Clegg. 1991. Consequences of floral variation for male and female reproduction in experimental populations of wild radish, Raphanus sativus L. Evolution 45:268-280.

Stephenson, A. G. 1981. Flower and fruit abortion: proximate causes and ultimate functions. Annual Review of Ecology and Systematics 12:253-279.

Stephenson, A. G., and R. I. Bertin. 1983. Male competition, female choice, and sexual selection in plants. Pages 109149 in L. Real, editor. Pollination biology. Academic Press, Orlando, Florida, USA.

Sutherland, S. 1986. Patterns of fruit-set: what controls fruitflower ratios in plants? Evolution 40:117-128.

Thomson, J. D. 1981. Spatial and temporal components of resource assessment by flower-feeding insects. Journal of Animal Ecology 50:49-59.

1988. Effects of variation in inflorescence size and 
floral rewards on the visitation rates of traplining pollinators of Aralia hispida. Evolutionary Ecology 2:65-76.

Waddington, K. D. 1983. Foraging behavior of pollinators. Pages 213-239 in L. Real, editor. Pollination biology. Academic Press, Orlando, Florida, USA.

Waser, N. M. 1979. Pollinator availability as a determinant of flowering time in Ocotillo (Fouquieria splendens). Oecologia 39:107-121.

- 1983. The adaptive nature of floral traits: ideas and evidence. Pages 241-285 in L. Real, editor. Pollination biology, Academic Press, Orlando, Florida, USA.

Waser, N. M., and M. V. Price. 1983. Optimal and actual outcrossing in plants, and the nature of plant-pollinator interaction. Pages 341-359 in C. E. Jones and R. J. Little, editors. Handbook of experimental pollination biology. Scientific and Academic Editions, New York, New York, USA.
Waser, N. M., and M. V. Price. 1991. Outcrossing distance effects in Delphinium nelsonii: pollen loads, pollen tubes, and seed set. Ecology 72:171-179.

Webb, C. J. 1984. Constraints on the evolution of plant breeding systems and their relevance to systematics. Pages 249-270 in W. F. Grant, editor. Plant biosystematics. Academic Press, Ontario, Canada.

Wilkinson, L. 1986. SYSTAT: the system for statistics. SYSTAT, Evanston, Illinois, USA.

Willson, M. F., and P. W. Price. 1977. The evolution of inflorescence size in Asclepias (Asclepiadaceae). Evolution 31:495-511.

Young, H. J., and M. L. Stanton. 1990. Influences of floral variation on pollen removal and seed production in wild radish. Ecology 71:536-547. 